\title{
Impalement Injury with Transanal Prolapse of Bowel Content Due to Intraperitoneal Rectal Tear
}

\author{
J. M. V. Amarjothi • Rajkumar Williams • S. A. Inpharasun
}

Received: 24 July 2012 / Accepted: 3 December 2012 /Published online: 26 January 2013

(C) Association of Surgeons of India 2013

\begin{abstract}
A 48-eight-year-old female patient came with prolapse of small intestines per rectum (Fig. 1) due to impalement injury with iron rod at a construction site. As the patient was hemodynamically unstable, she was taken for emergency laparotomy. A large rent in the intraperitoneal rectum was found (Fig. 2), with prolapse of intestines. Luckily for the patient, there was no other intra-abdominal organ injury. As there was no fecal contamination at all, a decision against proximal colostomy was made. The rent was closed in two layers after re-placing the small bowel contents with thorough lavage. Patient made a swift recovery thereafter.
\end{abstract}

Keywords Impalement injury $\cdot$ Small bowel prolapse · Rectal perforation

A middle-aged female patient came with history of prolapse of small bowel contents due to impalement injury at a construction site (Fig. 1). The patient was taken for emergency surgery due to hemodynamic instability. A large perforation of size $4 \times 4 \mathrm{~cm}$ in the intraperitoneal region (Fig. 2) was found. There were no other injuries. The bowel contents were re-placed in the abdomen after thorough lavage. The rent was closed by a two-layer technique. As there was no fecal spillage, colostomy was not done. The patient later made a swift recovery.

J. M. V. Amarjothi $(\triangle) \cdot$ R. Williams $\cdot$ S. A. Inpharasun

Madras Medical College, Chennai, India

e-mail: drmosesvikramamarjothi@hotmail.com

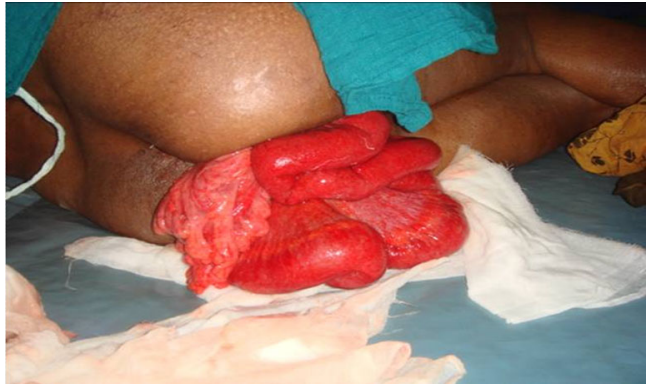

Fig. 1 Patient presented with prolapse of bowel contents per rectum due to injury

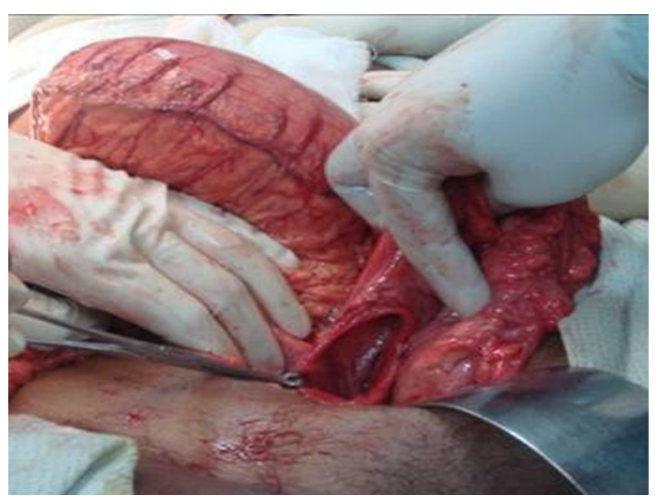

Fig. 2 Intraoperative picture showing the perforation involving the rectum 